\title{
STRUCTURE PROJECT APPLICATION PELAYANAN PASIEN RAWAT JALAN PADA RSIA SELARAS
}

\author{
Maimunah $^{1}$ \\ Septiyan $^{2}$ \\ Bayu Setiawan $^{3}$ \\ Dosen STMIK Raharja Tangerang ${ }^{1}$, Mahasiswa STMIK Raharja Tangerang ${ }^{2,3}$ \\ Jl. Jendral Sudirman No.40, Modernland, Tangerang ${ }^{1,2,3}$ \\ email :maimunah@ raharja.info ${ }^{1}$, septiyan@ raharja.info ${ }^{2}$, bayu.setiawan@ raharja.info ${ }^{3}$
}

\begin{abstract}
ABSTRAK
Kebutuhan informasi dan pelayanan yang cepat, akurat, dan memuaskan pada era modern seperti saat ini, dirasa semakin dibutuhkan oleh setiap instansi. Khususnya RSIA Selaras yang bergerak dalam bidang jasa kesehatan dan pelayanan yang setiap saat selalu berhubungan dengan masyarakat atau customer. Masalah yang terjadi pada instansi khususnya RSIA Selaras ini adalah sistem pelayanan pasien rawat jalan yang belum baik karena masih terjadi kesalahan dalam pencarian data pasien, pembuatan laporan, akumulasi biaya pelayanan dan belum mendukung penggunaan teknologi informasi dalam hal ini client server. Dengan dibangunnya sistem yang optimal akan memperkecil masalah yang sering terjadi dalam pelayanan pasien rawat dan sistem dapat berjalan dengan lancar. Merancang sistem informasi pelayanan pasien secara komputerisasi akan dapat menjamin adanya ketetapan waktu untuk menghasilkan informasi serta dapat mengontrol pendapat rumah sakit secara otomatis karena sebagian besar data di simpan dalam file serta mendukung sistem komputerisasi. Perancangan sistem informasi pelayanan pasien rawat jalan yang dirancang dengan menggunakan Microsoft Visual Basic 6.0, database menggunakan MySQL. Diharapkan dengan dirancangnya sistem informasi pelayanan pasien rawat jalan ini bisa membantu memecahkan permasalahan yang dihadapi RSIA Selaras. Untuk memperoleh datadata yang diperlukan selama penelitian, penulis menggunakan beberapa metode, antara lain : wawancara, observasi, dan studi pustaka. Data yang diperoleh kemudian dianalisa dan digambarkan dengan menggunakan metode UML ( Unified Modeling Language ), dan metode perancangan dengan analisa terhadap sistem berjalan untuk mendeteksi masalah yang ada. Maka perlu adanya suatu pengolahan data dan sistem semi manual ke sistem pengolahan data yang komputerisasi dengan menggunakan suatu pemrograman pelayanan pasien rawat jalan agar dapat memudahkan proses pelayanan pasien rawat jalan.
\end{abstract}

Kata kunci : Perancangan Sistem Informasi, Visual Basic 6.0., MySQL, UML

\section{ABSTRACT}

The need of information and services quickly, accurately, and satisfy the modern era like today, felt increasingly required by each agency. Especially RSIA Selaras engaged in health services and services at any time is always in touch with the community or customer. Problems that occur in the institution are particularly RSIA Selaras outpatient care system that is not good because it is still an error occurs in the search for patient data, preparation of reports, the accumulated cost of service and does not support the use of information 
technology in this case the client server. With the construction of the optimal system would minimize the problems that often occur in patient care and the system can run smoothly. Designing the information system of computerized patient care will be able to ensure the provision of time to generate information and can control the opinion of the hospital automatically because most of the data stored in the file as well as the support of the computerized system. Information system design services outpatient designed using Microsoft Visual Basic 6.0, using a MySQL database. It is expected the system he designed outpatient care information might help solve the problems faced RSIA Selaras. To obtain the data needed for the study, the authors used several methods, among others: interviews, observation, and literature. The data obtained and analyzed and described using UML (Unified Modeling Language), and design method by analyzing the running system to detect problems. Hence the need for a data processing and semi-manual system to a computerized data processing system by using a programming outpatient services in order to facilitate the process of outpatient services.

Keywords: Information Systems Design, Visual Basic 6.0., MySQL, UML 


\section{PENDAHULUAN}

Dengan berkembangnya teknologi yang semakin pesat. Salah satunya penerapan ilmu pengetahuan teknologi dan aplikasi-aplikasi komputer yang semakin baik di setiap instansi. Dengan adanya teknologi dapat membantu tugas-tugas penting yang menyangkut data jumlah besar pada suatu perusahaan, membantu setiap pekerjaan dalam bidang komputerisasi baik di dunia industri, pendidikan, pelayanan, kesehatan dan lain sebgainya.

RSIA Selaras, merupakan suatu badan usaha yang bergerak dibidang pelayanan kesehatan dan pengobatan pasien. Pencatatan persediaan obat sangat perlu suatu penenganan khusus agar tidak terjadi kekliruan pencatatan dan pelaporan data, seperti yang sering terjadi selama ini, terutama dalam keterlambatan dalam pelayanan dan pelaporan omset kepada pihak management, pembuatan nota pelayanan yang memerlukan waktu yang cukup lama, dikarenakan dilakukan secara semi manual, juga pencatatan pelaporan yang sering terlambat dikarenakan pencatatan data dilakukan dengan menggunakan Microsoft Excel baik laporan harian, mingguan dan bulanan yang memerlukan waktu yang cukup lama.

Berkembangnya instansi tersebut, maka perlu adanya suatu pengolahan data dan sistem semi manual ke sistem pengolahan data yang komputerisasi dengan menggunakan suatu pemrograman.

\section{PERMASALAHAN}

Dalam penelitian yang dilakukan pada RSIA Selaras terdapat beberapa permasalahan yang terjadi di RSIA Selaras tersebut, yang diantaranya adalah proses pelayanan khususnya dalam rawat jalan masih bersifat manual sehingga membutuhkan waktu yang lama dalam pendaftaran pasien baru, pembuatan ID card pasien, pencarian data pasien yang sudah terdaftar, data riwayat pasien, laporan data pasien dan data- data obat yang berada di apotik.

Dari kesimpulan permasalahan diatas terdapat beberapa pertanyaan yang menyangkut permasalahan di atas yang diantaranya :

1. Apakah pelayanan khususnya rawat jalan yang ada sekarang sudah sesuai dengan prosedur yang ada?

2. Bagaimana merancang sistem informasi pelayanan rawat jalan?

3. Bagaimana sistem pelayanan dalam pemberian obat pada pasien rawat jalan ?

\section{LITERATURE REVIEW}

Banyak penelitian yang sebelumnya yang sebelumnya dilakukan mengenai pelayanan pasien rawat jalan. Beberapa literature review sebagai berikut :

1. Penelitian yang dilakukan oleh Endang Hermawati (2010)[16]. Penelitian ini dilakukan oleh Endang Hernawati [2010], yang berjudul "SISTEM INFORMASI RAWAT JALAN PADA RUMAH SAKIT KARANG ANYAR". Pada penelitian ini penulis menempatkan tujuannya dengan membuat sistem informasi pelayanan Rawat Jalan untuk memberikan informasi tentang rawat jalan secara mudah, cepat dan tepat untuk meningkatkan proses kerja RSUD yang semula manual menjadi terkomputerisasi dan menghasilkan laporan yang terperinci. Kelebihan dari program ini adalah dapat memberikan informasi pada masyarakat yang ingin berobat, tampilan program ini interface yang menarik.

2. Penelitian yang dilakukan oleh Lydia Adriani (2009)[15]. Penelitian ini dilakukan oleh Lydia Andriani dari Universitas Sumatera Utara, pada tahun 2009 yang berjudul "Sistem Informasi Rawat Jalan Di Rumah Sakit Dengan Menggunakan Program Komputer" Penelitian ini menjelaskan sebuah program komputer sebagai pendaftaran pasien rawat 
jalan menggunakan Microsoft Visual Basic 6.0 yang bertujuan untuk memudahkan proses pelayanan pada pasien dan juga memudahkan pihak rumah sakit untuk melayani pasien. Keunggulan pada program ini memudahkan pada staft pendaftaran pasien dalam registrasi kunjungan pasien rawat jalan serta mempermudah dalam pembuatan laporan, memberikan kemudahan pada pihak rumah sakit dalam meningkatkan kualitas pelayanan rumah sakit serta mempermudah dalam mengambil keputusan manajerial.

3. Penelitian ini dilakukan oleh Adhi Susano (2014)[19]. Penelitian yang telah dijalankan oleh Adhi Susano dkk. [2014] Penelirian yang telah dijalankan oleh Adhi Susano dkk. berjudul "IMPLEMTASI SISTEM INFORMASI REKAM MEDIS DENGAN MENGGUNAKAN FAST (Framework For The Application Of System Techniquest) UNTUK MENDUKUNG EVALUASI PELAYANAN RUMAH SAKIT UMUM DI TANGERANG". Pada penelitian ini penulis memaparkan tujuannya untuk menemukan solusi perbaikan untuk meningkatkan mutu pelayanan Rumah Sakit, yaitu menghasilkan rancangan sistem informasi rekam medis melalui pendekatan FAST (Framework For The Application Of System Techniquest) yang dapat digunakan untuk mendukung evaluasi pelayanan Rumah Sakit Umum Tangerang. Sistem informasi rekam medis yang sedang digunakan belum berjalan dengan baik sehingga untuk mengevaluasi pelayanan kesehatan dengan kegiatan pengumpulan, pengolahan dan pelaporan datamasih sulit dilaksakan akibatnya sistem yang sedang digunakan tersebut belum dapat menghasilkan laporan yang dibutuhkan oleh pihak manajemen secara rutin. Hasil penelitian adalah sistem informasi Rekam Medis yang dikembangkan di RS Islam Asshobirin yang dapat meningkatkan mutu pelayanan, hal ini dapat dilihat dari laporan bulanan yang dapat dicetak tepat waktu dan lengkap sesuai kebutuhan bagian manajemen.

4. Penelitian ini dilakukan oleh Ollynia Devega (2014)[18]. Penelitian ini dilakukan oleh Ollynia Devega [2014], yang berjudul PROTOTYPE SISTEM INFORMASI AKUTANSI PEMBAYARAN BIAYA RAWAT INAP PADA RS DINDA JATIUWUNG TANGERANG. Penelitian ini membahas mengenaing data yang kurang akurat untuk ruangan yang tersedia atau penuh serta penggunaan alat tersebut dan nota hanya menggunakan nota hal tersebut dapat mengakibatkan terjadinya kesalahan dalam pencatatan data. Sehingga dilakukan penelitian dan perancangan sistem yang diharapkan dapat membantu proses pengajuan ruangan, penggunaan nota transaksi dan dapat membantu perawat unit rawat inap dalam menghitung biaya perawatan.keunggulan dari program ini Tampilan interface yang menarik dan lebih dari user friendly sehingga lebih mudah digunakan oleh pengguna.

5. Penelitian ini dilakukan oleh Dwi Pra Satriawan (2014)[17]. Penelitian ini dilakukan oleh Dwi Pra Satriawan [2014], yang berjudul "PERANCANGAN SISTEM INFORMASI RADIOLOGI UNTUK MEDICAL CHECK UP REKANAN BERBASIS WEB PADA MITRA MEDIKA CENTER". Penelitian ini membahas mengenai alat mengolah data informasi pada Mitra Medika Center masih menggunakan excel, data belum up to date dan belum terintegrasi dengan data medical check up. Untuk itu dilakukan penelitian dan perancangan sistem yang diharapkan dapat membantu untuk mengurangi biaya pembelian kertas, dan dapat dugnakan secara online, dan data dapat di update dan dikembangkan. Keunggulan program ini Tampilan interface yang menarik dan lebih dari user friendly sehingga lebih mudah digunakan oleh pengguna, mudah digunakan dan dipahami oleh pengguna.

Dari 5 (lima) literature review yang ada, masih banyak penelitian yang mengenai sistem pelayanan di rumah sakit oleh karena itu, untuk menindak lanjuti peneliti sebelumnya 
seperti yang dikemukakan diatas, maka dilakukan penelitian tentang pelayanan di rumah sakit.

\section{LANDASAN TEORI}

\section{Pengertian Perancangan Sistem}

Menurut Stair (2010:497)[1], Perancangan sistem adalah fase pengembangan sistem yang mendifinisikan bagaimana sistem informasi akan melakukan perancangan untuk mendapatkan solusi pemecahan masalah.

Menurut Aisyah dkk didalam Jurnal CCIT Vol. 4 no 2 (2011:203)[2], "Perancangan sistem yaitu tahap untuk melakukan perancangan aplikasi, yang dapat 3 (tiga) tahapan perancangan seperti perancangan interface, perancangan isi, dan perancangan program".

Design system merupakan tahap yang dilakukan seteah melakukan tahap analisis sistem, dan mendapatkan gambaran jelas tentang apa yang harus dilakukan, atau tahap selanjutnya yang harus dilakukan adalah membuat desain sistem.

\section{Pengertian Pelayanan}

Menurut Fandy Tjiptono (2012:4)[3] pelayanan (service) bisa dipandang sebagai sebuah sistem yang terdiri atas dua komponen utama, yakni service operations yang kerap kali tidak tampak atau tidak diketahui keberadaannya oleh pelanggan (back office atau backstage) dan service delivery yang biasanya tampak (visible) atau diketahui pelanggan (sering disebut pula front office atau frontstage).

Menurut Rahmayanty (2010:12)[4] pelayanan "merupakan sistem melakukan sesuatu yang dibutuhkan publik, organisasi, pemerintahan atau perusahaan swasta dalam periode waktu yang lama, tidak berwujud, dan memudahkan".

Menurut Kotler (2002:83)[5] definisi pelayanan adalah setiap tindakan atau kegiatan yang dapat ditawarkan oleh suatu pihak kepada pihak lain, yang pada dasarnya tidak berwujud dan tidak mengakibatkan kepemilikan apapun. Produksinya dapat dikaitkan atau tidak dikaitkan pada satu produk fisik. Pelayanan merupakan perilaku produsen dalam rangka memenuhi kebutuhan dan keinginan konsumen demi tercapainya kepuasan pada konsumen itu sendiri. Kotler juga mengatakan bahwa perilaku tersebut dapat terjadi pada saat, sebelum dan sesudah terjadinya transaksi. Pada umumnya pelayanan yang bertaraf tinggi akan menghasilkan kepuasan yang tinggi serta pembelian ulang yang lebih sering. Kata kualitas mengandung banyak definisi dan makna, orang yang berbeda akan mengartikannya secara berlainan tetapi dari beberapa definisi yang dapat kita jumpai memiliki beberapa kesamaan walaupun hanya cara penyampaiannya saja biasanya terdapat pada elemen sebagai berikut: 1. Kualitas meliputi usaha memenuhi atau melebihkan harapan pelanggan. 2. Kualitas mencakup produk, jasa, manusia, proses dan lingkungan 3. Kualitas merupakan kondisi yang selalu berubah.

\section{Pengertian Rumah Sakit}

Menurut Peraturan Menteri Kesehatan Republik Indonesia No. 340/MENKES/PER/III/2010[6], "Rumah Sakit adalah institusi pelayanan kesehatan yang menyelenggarakan pelayanan kesehatan perorangan secara paripurna yang menyediakan pelayanan rawat inap, rawat jalan dan gawat darurat".

\section{Pengertian Visual Basic}

Menurut Eko Koswara (2013:9)[7], Visual Basic adalah sebuah pemrograman untuk membuat aplikasi visual bebasiskan sistem operasi Microsoft Windows. 
Menurut MADCOMS (2008:1)[8],"Microsoft Visual Basic merupakan salah satu pemrograman visual yang memiliki bahasa pemograman yang cukup populer dan mudah untuk dipelajari”.

Menurut Kusrini (2007:171)[9],"Visual basic adalah salah satu pemrograman komputer". Bahasa pemrograman adalah perintah-peintah yang dimengerti oleh komputer untuk melakukan tugas-tugas tertentu. Visual basic merupakan salah satu development tool, yaitu alat bantu untuk membuat berbagai macam program komputer, khusunya yang menggunakan sistem operasi windows.

\section{Definisi MySQL}

\section{Pengertian MySQL}

Menurut Deni Sutaji (2012:40)[10], MySQL adalah DBMS yang didistribusikan secra gratis dibawah lisensi dari general public license (GPL), dimana setiap orang bebas untuk menggunakanya tetapi tidak boleh untuk dijadikan program induk turunan bersifat close source (komersial). Menurut Deni Sutaji beberapa keunggulan dari MySQL.

1. Portability: dapat berjalan stabil pada berbagai system operasi, diantaranya windows, linux, FreeBSD, Mac OS Xserver, solaris, dan asigma.

2. Open source : didistribusikan secara gratis dibawah lisensi dari general public license dimana setiap orang bebas untuk menggunakanya tetapi tidak boleh menggunakan MySQL untuk dijadikan induk turunan yang bersifat close source (komersial).

3. Multi user : dapat digunakan oleh beberapa user dalam waktu yang bersamaan.

4. Performance tuning : mempunyai kecepatan yang tinggi dalam menangani quer.

5. Column types : memiliki tipe data yang sangat komplik.

6. Command dan function : memiliki operator dan fungsi penuh yang mendukung select dan where dalam query.

7. Security : memiliki beberapa lapisan sekuritas seperti tingkat subnet mask, hostname, privilege user dengan system perijinan yang mendetailserta password yang ter-enkripsi.

8. Scalability dan limits : mampu menangani basis data dalam jumlah besar.

9. Localization: dapat mendeteksi pesan kesalahan (error code) pada klien dengan menggunakan lebih dari 20 bahasa.

10. Connectivity: dapat melakukan koneksi dengan klien menggunakan protocol TCP/IP, Unix Socket, Named pipes.

11. Interface memiliki antarmuka terhadap berbagai aplikasi dan bahasa pemprograman dengan menggunakan fungsi API.

12. Clients dan tools: dilengkapi dengan berbagai tool yang dapat digunakan untuk administrasi basis data sekaligus dokumen petunjuk online.

13. Struktur table: memiliki struktur table yang lebih fleksibeldalam menangani alter table dibandingkan dengan postgre SQL dan oracle.

\section{Metode Penelitian}

Metode penelitian ini adalah dengan menggunakan menggunakan metodologi waterfall yang dibatasi dan hanya dilakukan hingga tahap implementasi atau coding. Untuk memperoleh data yang diperlukan metode pengumpulan data yang digunakan adalah sebagai berikut :

1. Metode Observasi

Melakukan tinjauan langsung ke tempat instansi yang ingin diteiti serta mengumpulkan data informasi mengenai pelayana pasien rawat jalan.

2. Metode Wawancara 
Melakukan tanya jawab dengan yang bersangkutan dan yang berwenang untuk memperoleh data informasi yang diperlukan dan mengetahui alur kerja pada sistem tersebut.

3. Metode Studi Pustaka

Mencari data-data yang berkaitan dengan masalah-masalah yang dibahas dan diperoleh dari buku-buku dan media internet.

\section{PEMBAHASAN}

\section{Alternatif Pemencahan Masalah}

Untuk mengatasi permasalahan tersebut di atas, maka di rancang lah sistem informasi pelayanan pasien berbasis DBMS dengan bahasa pemrograman Visual Basic 6.0, yang dapat digunakan oleh bagian Pendaftaran pasien rawat jalan, Apotik, serta Kasir untuk menyajikan informasi pelayanan pasien rawat jalan secara terkomputerisasi dan terintegrasi antara unit kerja yang satu dengan yang lainnya.

Program tersebut nantinya akan menampilkan menu pendaftaran pasien baru dan registrasi pasien lama pada bagian pendaftaran serta informasi registrasi pasien perhari, minggu, bulan, serta pertahun sebagai metode pencarian data pasien pada bagian pendaftaran.

Bagian Apotik program tersebut akan menampilkan menu pencarian data pasien sesuai dengan registrasi pendaftaran pasien yang diregistrasi oleh bagian pendaftaran serta menampilkan menu transaksi penjualan obat yang akan di berikan kepada pasien.

Pada bagian kasir menampilkan menu penginputan tindakan yang diberikan pada poli pelayanan pasien yang dilakukan oleh dokter ataupun perawat sehingga semua pelayanan yang diberikan dapat diakumulasikan sehingga seluruh biaya yang akan ditanggung oleh pasien pada bagian kasir sebagai tempat pembayaran pasien, diharapkan dengan sistem yang terintegrasi, yang dipusatkan pada satu bagian yaitu bagian kasir untuk keseluruhan biaya pelayanan maka kebocoran pendapatan akan dapat diatasi.

\section{Rancangan Sistem yang diusulkan}

Untuk menganalisa sistem yang dibuat dan yang ingin diusulkan pada penelitian ini digunakan program Visual Paradigm 6.4 Enterprise Edition untuk menggambarkan Usecase Diagram, Activity Diagram, dan Sequence Diagram 


\section{Use Case Diagram yang diusulkan}

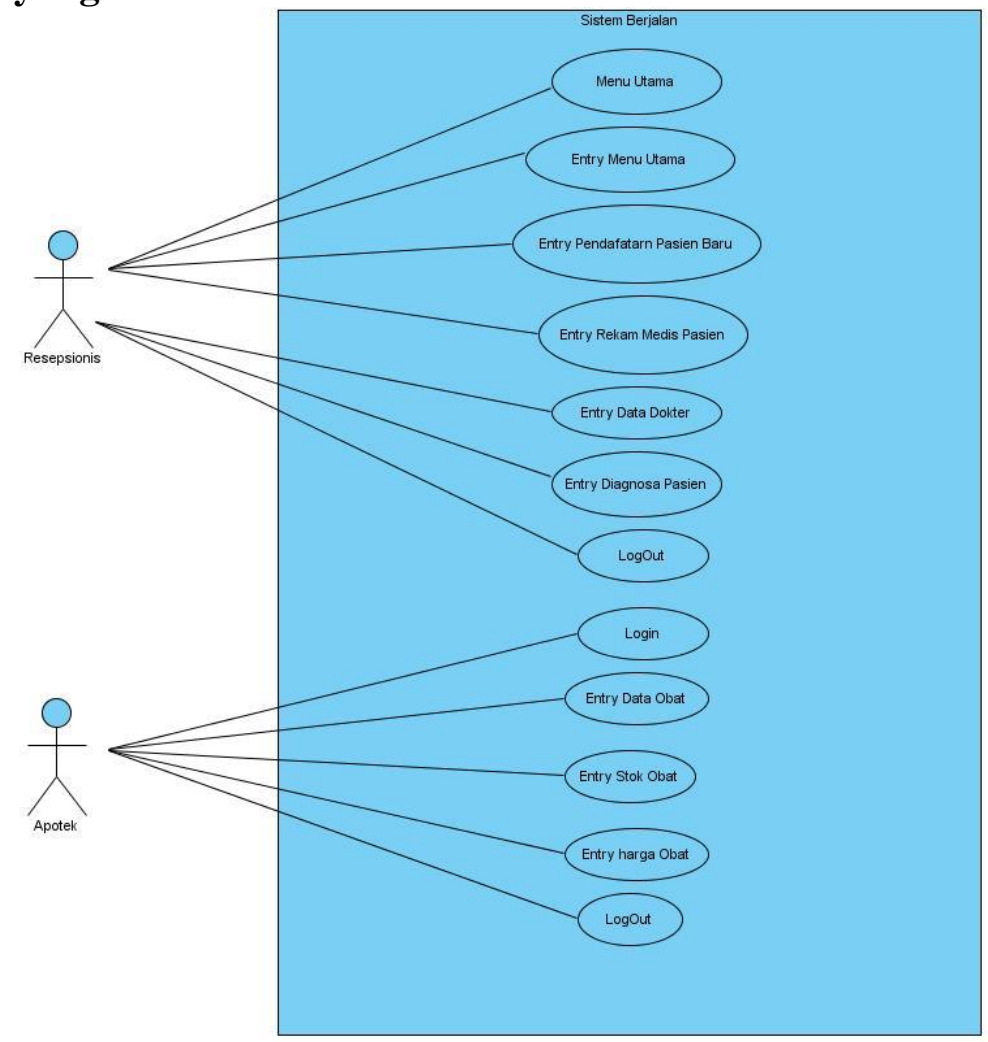

Gambar 1 Use Case Diagram

Berdasarkan gambar 1 Use Case Diagram pada sistem informasi pelayanan pasien rawat jalan terdapat:

1. 1 (satu) sistem rawat jalan

2. 2 (dua) actor yang melakukan kegiatan, diantaranya Resepsionis, dan Apoteker 12 (dua belas) use case yang dilakukan oleh para actor

\section{Activity Diagram yang diusulkan}

1. Activity Diagram Resepsionis

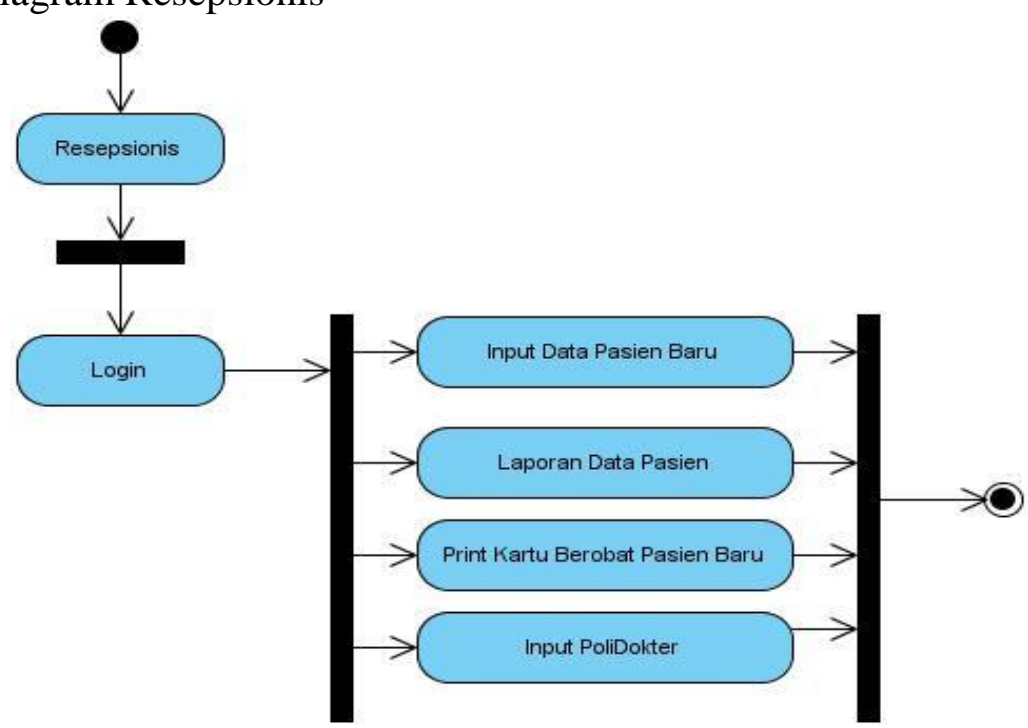

Gambar 2 activity diagram resepsionis pada sistem 
Berdasarkan pada gambar 2 activity Diagram pada Resepsionis terdapat :
a. 1 (satu) Intial Node, objek yang diawai
b. 6 (enam) action, state dari sistem mencerminkan eksekusi dari suatu aksi
c. 1 (satu) Final State, objek yang diakhiri

2. Activity Diagram Apoteker

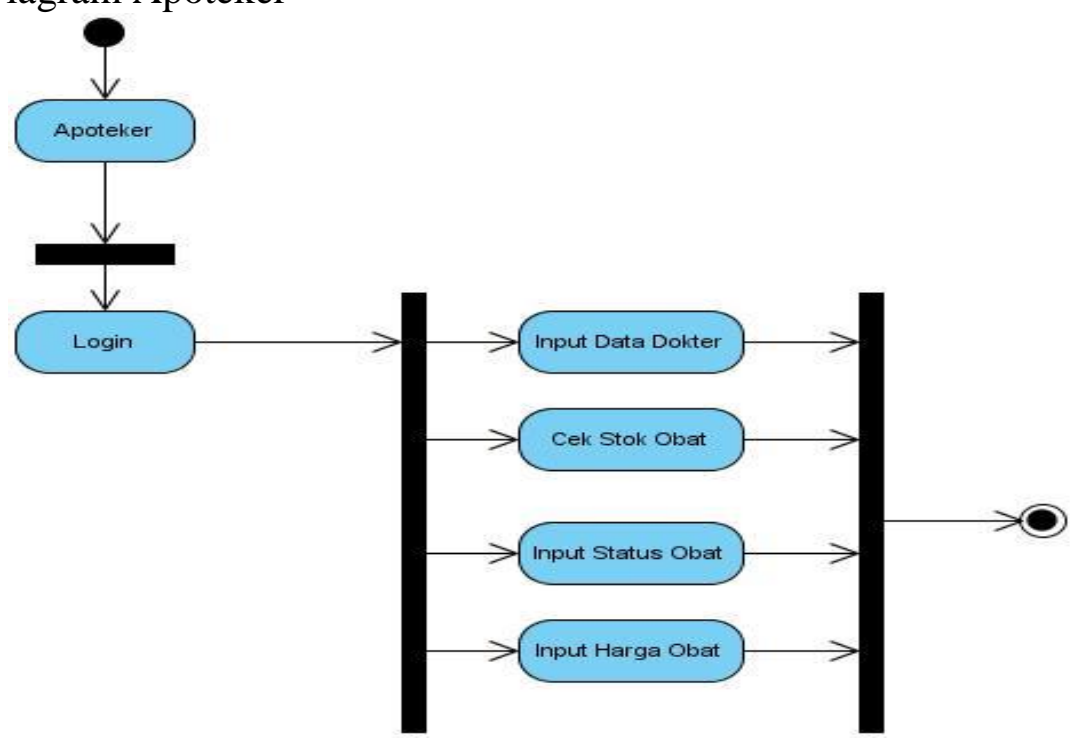

Gambar 3 activity diagram apoteker pada sistem

Berdasarkan pada gambar 2 activity Diagram pada Resepsionis terdapat :

a. 1 (satu) Intial Node, objek yang diawai

b. 6 (enam) action, state dari sistem mencerminkan eksekusi dari suatu aksi

c. 1 (satu) Final State, objek yang diakhiri

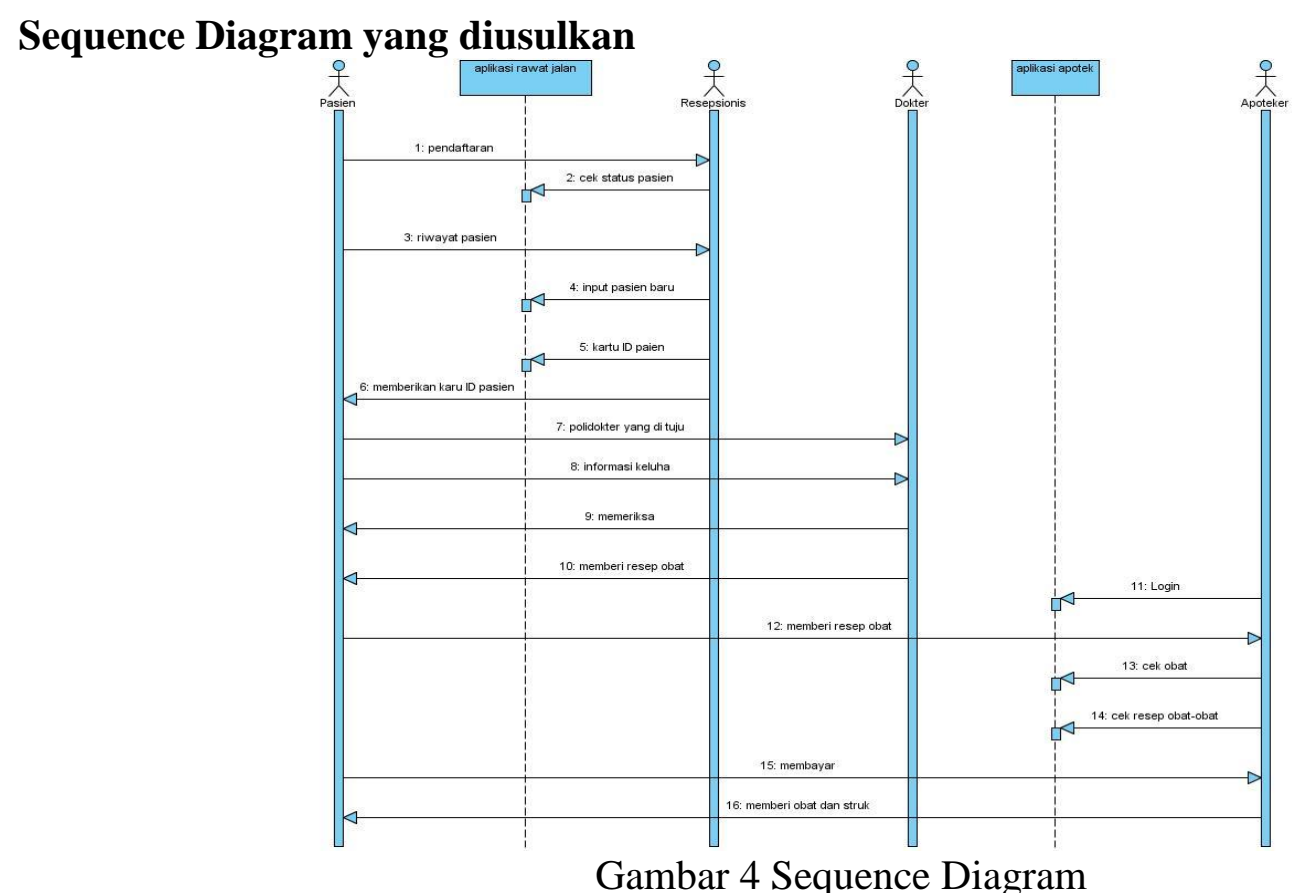

Berdasarkan gambar 4 Sequence Diagram pada sistem pelayanan pasien rawat jalan diatas, terdapat : 
a. 2 (dua) Lifeline antar muka yang saling berinteraksi, yaitu aplikasi rawat jalan dan aplikasi apoteker

b. 4 (empat) actor yang melakukan kegiatan, yaitu pasien, resepsionis, dokter, apoteker

c. 16 (enam belas) message spesifikasi dari komunikasi antar objek yang memuat informasi tentang aktifitas yang terjadi, kegiatan yang bisa dilakukan oleh para actor

\subsection{Implementasi}

Hasil dari implementasi sistem informasi interface dapat terlihat seperti pada gambar-gambar berikut :

1. Form Menu Utama

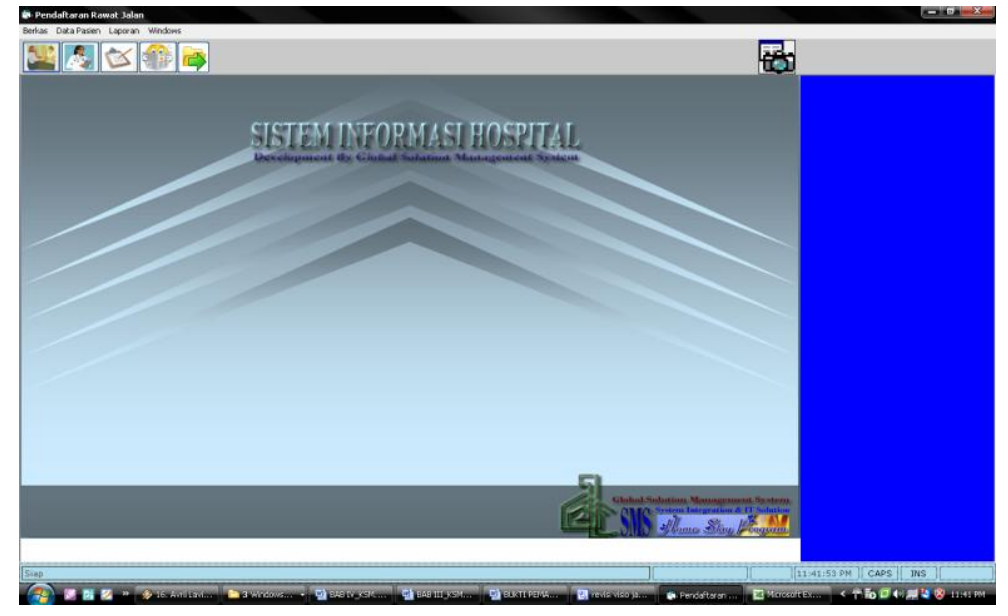

Gambar 5 Form Menu Utama

Gambar 5 Form Menu Utama menampilkan menu Utama pada bagian pedaftaran pasien, terdapat berkas, data pasien, laporan, dan windows. Pada menu berkas terdapat kelola dokter, kelola admin, kelola polidokter, dan keluar, pada menu data pasien terdapat pendaftaran pasien, pencarian data pasien, pada menu laporan terdapat laporan data pasien, laporan diagnosa pasien, dan laporan registrasi pasien, pada menu windows untuk mengganti desain tampilannya. Ada pun beberapa button yaitu pendaftaran pasien, data dokter, laporan, cetak nomor antrin, dan keluar. Aplikasi ini di desain disesuaikan dengan keinginan pihak instansi dan sesimple mungkin penampilannya agar mempermudah dalam menggunakan aplikasi ini dan dapat secara cepat mengerti dalam penggunakan aplikasi ini.

2. Form Input Data Pasien

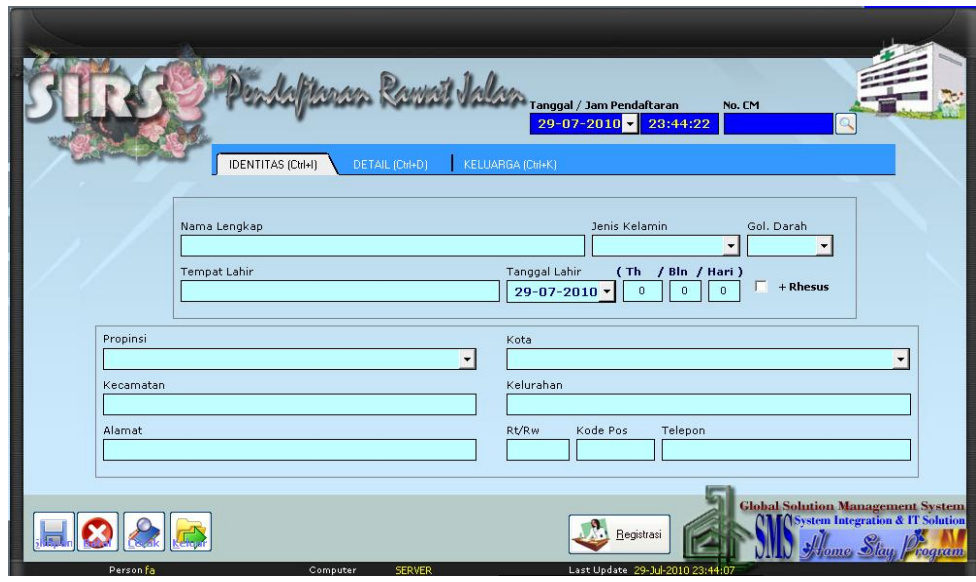

Gambar 6 Form Data Pasien 
Gambar 6 Form Data Pasien menampilkan pendaftaran untuk mendaftar pasien, form ini berfungsi untuk pendaftaran pasien rawat jalan, di form ini terdapat tanggal, jam, no.CM, terdapatnya tanggal, jam secara otomatis akan memudahkan pengguna agar tidak mengetik tanggal dan jam karena tanggal dan jam akan otomatis muncul sesuai tanggal dan jam hari pasien yang akan mendaftar. Form ipu data pasien terdapat button save, delete, search kembali dan registrasi pasien yang tentunya akan mempermudah pengguna dalam hal menyimpan data pasien, menghapus, dan search pasien yang sudah terdaftar. Form ini disesuaikan dengan pendaftaran tempat instansi tersebut karena untuk mempermudah pengguna dalam pemakaian aplikasi ini.

3. Form Registrasi Pasien

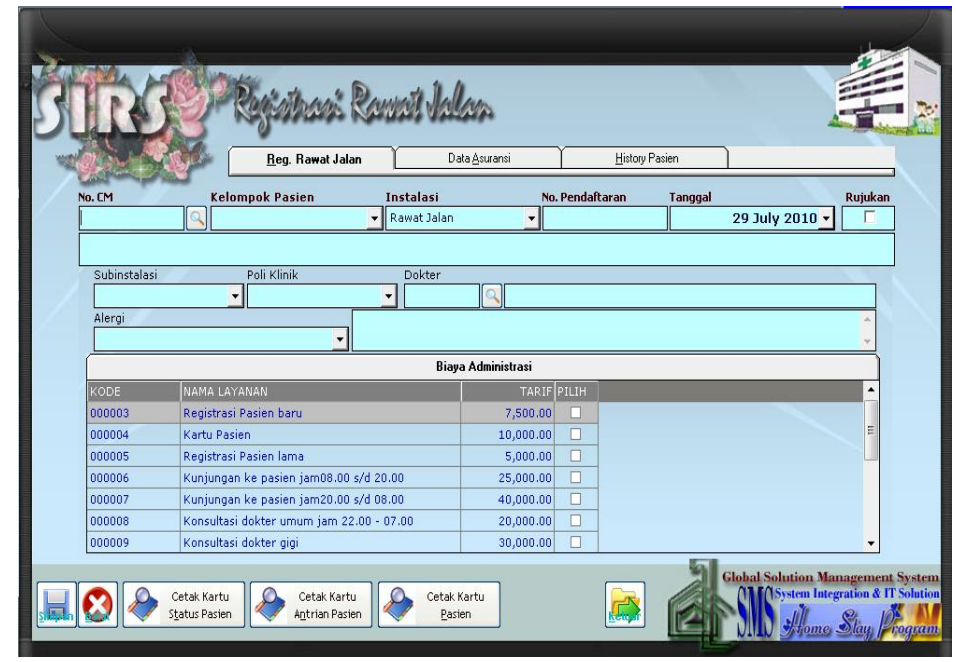

Gambar 7 Form Registrasi Pasien

Gambar 7 Form Registrasi Pasien menampilkan data biaya berobat pasien. Form ini terdapat beberapa button seperti Reg. Rawat Jalan, Data Asuransi, History Pasien, save, delete, cetak kartu pasien, cetak kartu antrian pasien baru, dan cetak kartu pasien. Reg. Rawat Jalan menampilkan data-data layanan dan tarif biaya yang sesuai dengan layanan yang akan mempermudah pengguna dalam mencari biaya pasien yang harus di bayar sesuai layanan yang pasien gunakan, Data Asuransi terdapat pasien yang mendaftar dengan menggunakan ansuransi karena pasien mendaftar dengan asuransi biaya bereda dengan biaya yang tidak menggunakan ansuransi, tampilan data asuransi tidak jauh beda dengan reg. rawat jalan, History pasien teradapat data-data pasien yang berkunjung pasien lama maupun pasien baru. Menggunakan aplikasi khusunya form registrasi pun di permudah dan disesuaikan dengan keinginan pihak instansi agar pengguna dapat mudah mengerti dalam hal pemakaian aplikasi khususnya form registrasi.

\section{Form Input Diagnosa}




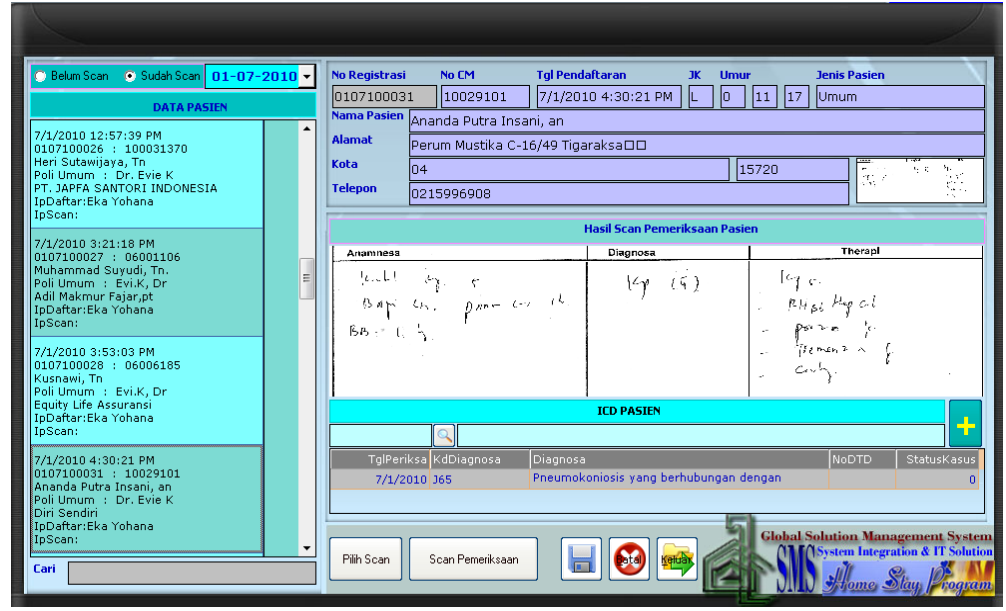

Gambar 8 Form Input Diagnosa

Gambar 8 Form Input Diagnosa menampilkan form input diagnosa. Form ini digunakan untuk menginput diagnosa pasien yang berobat. Form ini khusu untuk data-data diagnosa pasien yang berobat menggunanya pun sangat mudah, pengguna hanya mengetik di text search guna ingin mencari pasien yang sudah mendaftar dan akan muncul sesuai nama pasien yang kita cari. Data diagnosa pasien guna melengkapi data pasien yang berobat. Form ini terdapat beberapa button seperti save guna menyimpan data diagnosa pasien baru, delete guna mendelete pasien yang sudah tidak terdaftar, kembali untuk kembali ke form utama, button pilih scan untuk menscan form yang diisi oleh dokter untuk pasien yang berobat agar mempermudah pemakai agar tidak mengetik kembali, scan pemeriksa untuk menscan khususnya dalam pemeriksaan dari dokter agar mempermudah pemakai agar tidak mengetik ulang. Desain penampilannya pun disesuaikan keinginan instansi agar mudah dalam pemakainya.

5. Form Menu Utama Apotek

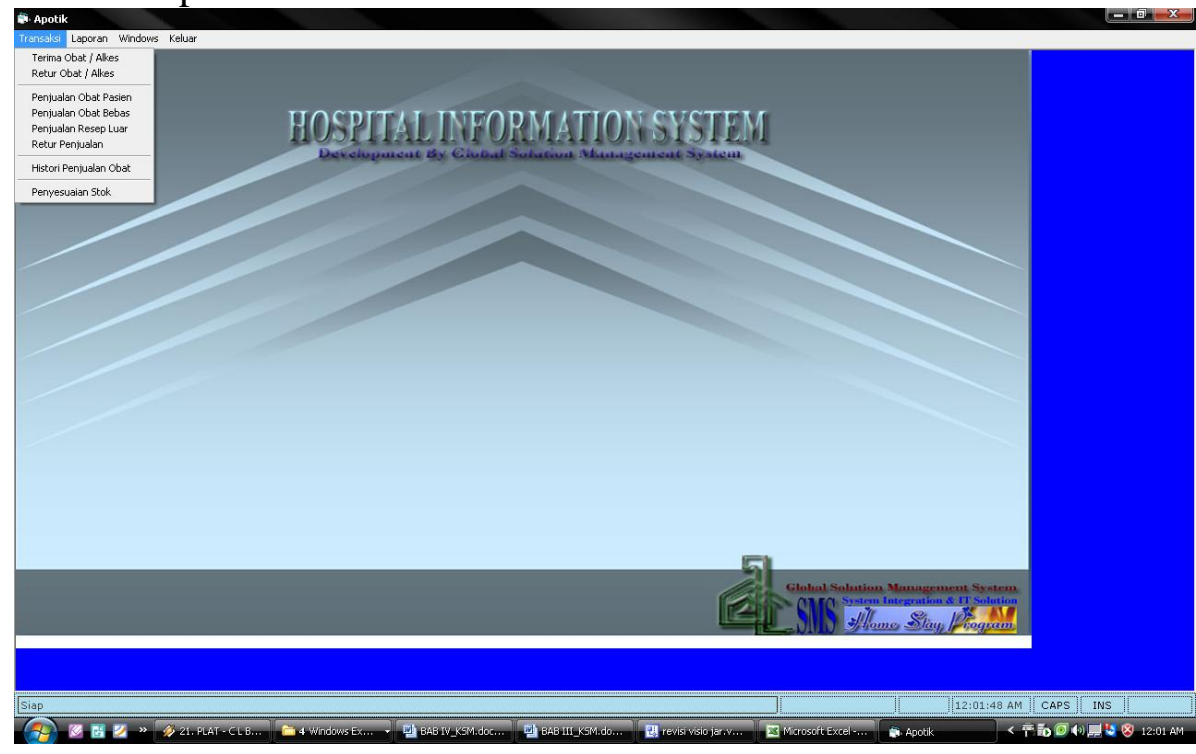

Gambar 9 Gambar Form Menu Utama Apotik

Gambar 9 Form Menu Utama Apotik menampilkan menu utama untuk bagian apotek. Form ini menampilkan menu-menu seperti menu transaksi yang terdapat terima obat, retur 
obat, penjualan obat pasien, penjualan obat bebas, penjualan resep luar, retur penjualan, histori penjualan obat dan penyesuaian stok, menu laporan terdapat laporan data obat masuk, laporan data obat terjual, dan laporan data stok obat, menu windows untuk mengubah template agar pengguna tidak bosan untuk mennguanakannya, dan yang terakhir menu keluar berguna untuk keluar dari aplikasi apotik, menu-menu tersebut menampilakan yang sesuai dengan nama menu-menu tersebut. Desain alikasi apotik pun disesuaikan dengan keinginan pihak instansi karena agar dapat mempermudah dan cepat mengerti dalam hal menggunakan aplikasi.

\section{Form Pencarian Pasien}

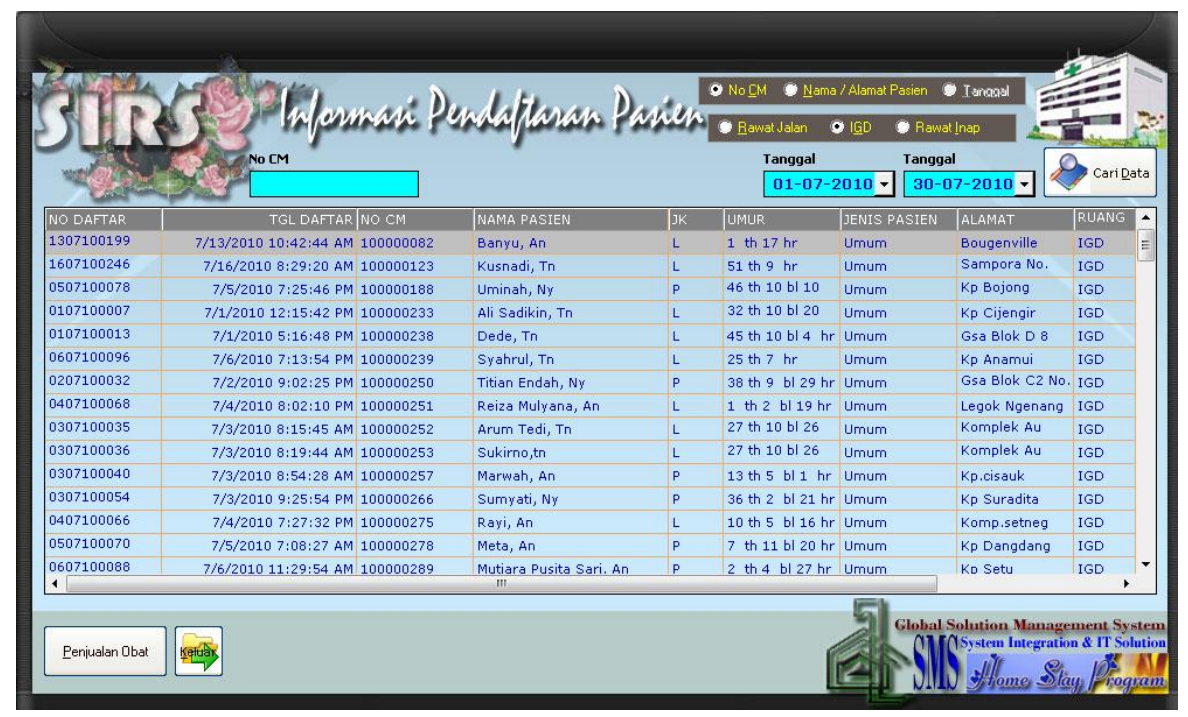

Gambar 10 Form Menu Pencarian Data Pasien

Gambar 10 Form Pencarian Menu Pencarian Data Pasien menampilkan data-data pasien yang sudah di input dan untuk pencarian data pasien. Di form ini terdapat Option Button seperti no $\mathrm{cm}$, nama atau alamat pasien tanggal, rawat jalan, igd, dan rawat inap. Option button digunakan untuk mempermudah mencari data pasien, data pasien baru ataupun data pasien lama, seusai option button yang dipilih pengguna. Dan terdapat pula combobox khusunya untuk tanggal dan button cari data digunakan agar mempermudah mencari data pasien yang terdaftar sesuai tanggal pasien mendafatar dan sampai tanggal pasien sudah tidak terdaftar. Form ini di desain simple tapi menarik agar pengguna dapat mudah mengerti dalam memakai aplikasi ini.

\section{KESIMPULAN}

Berdasarkan uraian diatas, dapat disimpulkan bahwa di RSIA Selaras belum menerapkan sistem pengolahan data dalam pengolahan data pasien, data pembayaran, data pasien lama dll, RSIA Selaras masih menggunakan semi manual sebagian dikerjakan dengan cara manual dan sebagian menggunakan komputer seperti data pasien yang menggunakan Microsoft Excel dan Word pegawai harus mengetik ulang untuk menginput data pasien baru dan lama, dan pegawai di RSIA Selaras selalu mengeluh karena sulitnya untuk membuat laporan data pasien, rekam medik, pemakaian obat pada pasien, dan biaya pendaftaran yang masuk tiap harinya. 
Dirancanglah sebuah program menggunakan program Visual Basic 6.0 dan databasenya menggunakan $M y S Q L$ untuk mempermudah pihak rumah sakit untuk melayani pasien sehingga pasien merasa puas dalam pelayanan di rumah sakit tersebut, mempermudah pasien untuk mendaftar sehingga pasien tidak harus untuk mengisi from pendaftaran pasien sendiri karena program ini terdapat pendaftaran sehingga yang mengisi pendaftaran adalah pihak rumah sakit untuk mengurangi antrian pada pasien yang ingin mendaftar, program ini pun terdapat Input Diagnosa Pasien untuk mempermudah dalam memasukan diagnosa pasien atau data-data pasien yang sudah terdaftar dan riwayat pasien yang sedang berobat jalan untuk mempermudah pihak rumah sakit untuk melihat data-data pasien dan serta biaya pasien, program ini pun dibuat untuk mempermudah pegawai di rumah sakit untuk membuat laporan-laporan seperti laporan data pasien, laporan diagnosa pasien, laporan biaya pasien, dan ID Card pasien, ID Card pasien untuk menandai pasien yang sudah terdaftar di rumah sakit, program ini pun terdapat program apotek untuk mempermudah pihak rumah sakit untuk melihat data-data obat, harga obat, stok obat, dan laporan-laporan data-data obat masuk, obat keluar, dan obat yang sudah kadarluasa.

\section{SARAN}

Dari analisa dan pengembangan sistem yang dilakukan penulis memberi solusi yang diharapkan mampu memberikan perbaikan terhadap sistem yang ada saat ini diantaranya adalah :

1. RSIA Selaras harus menerapkan sistem pengolahan data dengan cara mengelompokan data terlbih dahulu.

2. Kepada pihak manajemen RSIA Selaras dapat bekerja sama secara fleksibel, karena dalam sistem usulan ini banyak diadakan perubahan-perubahan aturan khususnya yang berhubungan dengan pengolahan data.

3. Membuat sebuah rancangan program aplikasi yang berbasis database dengan menggunakan Visual Basic dan diharapkan program aplikasi hasil karya penulis dapat dipergunakan sebagai solusi terhadap maslah-masalah yang ada pada sistem yang berjalan.

4. Kepada pimpinan RSIA Selaras, penulis berharap pimpinan perlu memberikan prosedur kerja tetap dibidang pengolahan data untuk mendukung kelancaran dan agar membantu proses implementasi dari kegiatan persiapan sampai dengan evaluasi sistem.

\section{DAFTAR PUSTAKA}

[1].Stair and Reynolds. 497:2010. "Definisi Analisa Sistem Adalah Fase Pengembangan Sistem". Jakarta

[2].Aisyah, Siti, Nawang Kalbuana. 2011. "Perancangan Aplikasi Akademik Teknologi Mobile Menggunakan J2ME". Vol. 4 No.2-Januari 2011 ISSN: 1978-8282 STMIK Raharja.

[3]. Tjiptono, Fandy. 2012. Service Management Mewujudkan Layanan Prima. Yogyakarta: CV Andi Offset. 
[4].Rahmayanty, Nina. 2010. Manajemen Pelayanan Prima. Yogyakarta: Graha Ilmu.

[5].Kotler, Philip. 2002. Manajemen Pemasaran di Indonesia : Analisis, Perencanaan, Implementasi dan Pengendalian. Salemba Empat. Jakarta.

[6].Menteri Kesehatan Republik Indonesia No. 340/MENKES/PER/III/2010.

[7]. Visual Basic for Beginner Ekko Koswara \& Wolf Community -cet. 1 yogyakarta: Penerbit MediaKom, 2013.

[8].Tim Divisi Penelitian dan Pengembangan MADCOMS. 2008. Microsoft Visual Basic 6.0 untuk pemula.

[9].Kusrini. 2007. Strategi Perancangan dan Pengelolaan Basis Data. Yogyakarta.

[10]. Deni Sutaji.2012. "Sistem Informasi Mini Market dengan PHP dan JQuery". Yogyakarta : lokomedia. 